\title{
Research on Financing Risks of Low-Rent Housing Based on Fuzzy Quality Synthetic Evaluation
}

\author{
Liu Yachen \\ School of Management \\ Shenyang Jianzhu University \\ Shenyan China \\ lyc@sjzu.edu.cn
}

\author{
Niu Siqi \\ School of Management \\ Shenyang Jianzhu University \\ Shenyang China \\ nsq0920@126.com
}

\author{
Ma Jian \\ School of Management \\ Shenyang Jianzhu University \\ Shenyang China \\ 2430418194@qq.com
}

\begin{abstract}
Financing risks of low-rent housing are influenced by many factors,and there are different levels of risk factors in different stages of development of the project. The index system of Financing risks of low-rent housing has been constructed in this paper where a index system of 5 criteria and 16 indicators has been proposed. Gray fuzzy comprehensive evaluation method has been elaborated and gray evaluation calculation process model is derived in detail. Finally, model is applied to the evaluation of the risk of lowrent housing project financing which makes it easy to prevent and control risk in each stages of the project.
\end{abstract}

Keywords-Low-rent housing; gray evaluation; index system; financing risks

\section{I.INTRODUCTION}

Some low-and middle-income families are unable to obtain housing through market means, so the government make effort to protect low-income families living in place through the construction of affordable housing.The lowcost housing is a very important part of China's housing security system as well as the most effective way to solve the most urgent need for housing by low-income populations. Currently, the construction of low-cost housing in China is relied on government investment which lead to a series of problems such as a shortage of funds for construction and lack of listings so that it can not meet the demand for housing for most low-and middle-income families ${ }^{[1-2]}$. Financing for the construction of low-rent housing projects is essential in order to solve the problem of government funds and attract a large number of social funds for construction .

PPP (Public-Private Partnership) is a public infrastructure project financing mode ${ }^{[3]}$.This mode encourages private enterprises to participate in the construction of low-rent housing and share low-rent housing finance risks with the government to mitigation government funding bottleneck problem. The financing of low-cost housing project time is relatively long, risky financing cause large amount of funds are needed for lowcost housing project and lots of parties should be involved in the construction of the project which has a direct impact on the feasibility of the project investment and construction. Evaluation study of low-rent housing PPP project financing risk is with practical significance which could make effective use of various types of social capital as well as provide the conditions for the smooth implementation of low-cost housing project ${ }^{[4]}$.

\section{CONSTRUCTION OF FINANCING RISK EVALUATION INDEX SYSTEM}

There is no uniform standard for risk financing of lowrent housing projects in our allocation currently. ${ }^{[5]}$ The index system in this paper based on the construction of China's low-rent housing PPP project finance practice examples to analyze and identify the various participants in the risk factor and put forward 5 criteria and 16 indicators. The Hierarchical model index system will be identified with AHP [6] as follows:

Table.1 The risk of low-rent housing project financing

\begin{tabular}{|c|c|c|}
\hline $\begin{array}{l}\text { Destinati } \\
\text { on Layer }\end{array}$ & $\begin{array}{l}\text { Criterion } \\
\text { Layer }\end{array}$ & Marker Bed \\
\hline \multirow{16}{*}{$\begin{array}{l}\text { The risk } \\
\text { of low- } \\
\text { rent } \\
\text { housing } \\
\text { project } \\
\text { financing } \\
\text { A }\end{array}$} & \multirow{5}{*}{$\begin{array}{l}\text { Credit Risk } \\
\text { A1 }\end{array}$} & Contractor’s Risk A11 \\
\hline & & Government Risk A12 \\
\hline & & Technical Risk A13 \\
\hline & & Funding Ability Risk A14 \\
\hline & & $\begin{array}{l}\text { Management Level Risk } \\
\text { A15 }\end{array}$ \\
\hline & \multirow{3}{*}{$\begin{array}{l}\text { Completion } \\
\text { Risk A2 }\end{array}$} & $\begin{array}{l}\text { Risk of Cost Overruns } \\
\text { A21 }\end{array}$ \\
\hline & & Risk of Project Delay A22 \\
\hline & & $\begin{array}{l}\text { Quality Substandard Risk } \\
\text { A23 }\end{array}$ \\
\hline & \multirow{3}{*}{$\begin{array}{l}\text { Managemen } \\
\text { t Risk A3 }\end{array}$} & $\begin{array}{l}\text { Business Cost Overruns } \\
\text { Risk A31 }\end{array}$ \\
\hline & & $\begin{array}{lll}\text { Operators } & \text { Quality } & \text { Risk } \\
\text { A32 } & & \end{array}$ \\
\hline & & Service Quality Risk A33 \\
\hline & \multirow{3}{*}{$\begin{array}{l}\text { Financial } \\
\text { Risk A4 }\end{array}$} & Exchange Rate Risk A41 \\
\hline & & Interest Rate Risk A42 \\
\hline & & Inflation Risk A43 \\
\hline & \multirow{2}{*}{$\begin{array}{l}\text { Natural, } \\
\text { Environmen } \\
\text { tal Risk A5 }\end{array}$} & $\begin{array}{l}\text { Earthquakes, Flood and } \\
\text { Other Force Majeure Risk } \\
\text { A51 }\end{array}$ \\
\hline & & Environmental Risk A52 \\
\hline
\end{tabular}

III. FINANCING RISK ASSESSMENT MODEL

Let $\mathrm{A}$ be the set of evaluation: $A=\left(A_{1}, A_{2}, \cdots, A_{i}\right)$,(i 
is the number of indicators, $\mathrm{i}=1,2 \ldots, \mathrm{n}$ ), among them $A_{i}=\left(A_{i 1}, A_{i 2}, \cdots, A_{i m}\right), m$ is the number of secondary indicators belongs to the $\mathrm{i}$-th level indicators.

\section{A. Determination of evaluation index weight}

Let $B=\left(b_{1}, b_{2}, \cdots, b_{i}\right)$ be the weight set of evaluation index , where $\sum_{i=1}^{n} b_{i}=1 \quad b_{i}$ denotes the evaluation indicators of the weight; meanwhile set the secondary index weight set: $\quad B_{i}=\left(b_{i 1}, b_{i 2}, \cdots, b_{i m}\right)$,where $b_{i m}(\mathrm{i}=1,2, \ldots, \mathrm{n})$ represents the proportion of the index $A_{i m}$ in A,while $\sum_{i=1}^{n} b_{i m}=1$.

B. different levels of $A_{i m}$ determined according to the criteria for the classification

Table 2 Rating Standard

\begin{tabular}{l|l}
\hline Standard & Implication \\
\hline 1 & Effect is poorer \\
\hline 2 & Results in general \\
\hline 3 & Effect is more noticeable \\
\hline 4 & Effect is very obvious \\
\hline $0.5 、 1.5 、 2.5 、 3.5$ & Between the two adjacent standard \\
\hline
\end{tabular}

C. Establishing the evaluation matrix $D$ according to the expert scoring

$R$ evaluators score to each evaluation based on scoring criteria $A_{i m}$, the evaluator's serial number is set as $\mathrm{k}(\mathrm{k}=1,2, \ldots, \mathrm{r})$

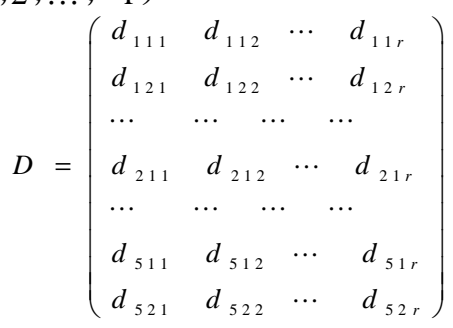

$d_{i m r}$ represents the $\mathrm{r}$-th reviewer ratings evaluation criteria layer of the i-th.

D.Gray degree and calculation of evaluation ${ }^{[7-8]}$.

I)Determine gray degree evaluation

Let gray degree $\mathrm{e}=4,3,2,1$ representing the four evaluation gray class "poor", "medium", "good", "excellent". Each category albino function corresponding to the gray number as follows ${ }^{[6]}$ :

The first category $(\mathrm{e}=1)$ :gray degree $\otimes_{1} \in[4, \infty]$, albino function is

$$
f_{1}\left(d_{i j k}\right)=\left\{\begin{array}{cl}
0 & x \notin[0, \infty] \\
\frac{d_{i j k}}{4} & x \in[0,4] \\
1 & x \in[4, \infty]
\end{array}\right.
$$

The second category $(\mathrm{e}=2)$ :gray degree $\otimes_{2} \in[0,3,6]$, albino function is

$$
f_{2}\left(d_{i j k}\right)=\left\{\begin{array}{cc}
0 & x \notin[0,6] \\
\frac{d_{i j k}}{3} & x \in[0,3] \\
\frac{6-d_{i j k}}{3} & x \in[3,6]
\end{array}\right.
$$

The third category $(\mathrm{e}=3)$ :gray degree $\otimes_{3} \in[0,2,4]$, albino function is

$$
f_{3}\left(d_{i j k}\right)=\left\{\begin{array}{cc}
0 & x \notin[0,4] \\
\frac{d_{i j k}}{2} & x \in[0,2] \\
\frac{4-d_{i j k}}{2} & x \in[2,4]
\end{array}\right.
$$

The fourth category $(\mathrm{e}=4)$ :gray degree $\otimes_{4} \in[0,1,2]$, albino function is

$$
f_{4}\left(d_{i j k}\right)=\left\{\begin{array}{cc}
0 & x \notin[0,2] \\
1 & x \in[0,1] \\
2-d_{i j k} & x \in[1,2]
\end{array}\right.
$$

II)Gray evaluation coefficient Calculation

The gray evaluation coefficient which $A_{\text {im }}$ belongs to the e-th evaluation gray class denoted as $x_{i m}^{e}$, where $x_{i j e}=\sum_{k=1}^{r} f\left(d_{i j k}\right)$.The total gray evaluation coefficient which $A_{i m}$ belongs to each evaluation gray class denoted as $X_{i m}$, where $X_{i j}=\sum_{e=1}^{4} x_{i j e}$

III)Gray evaluation weight vector and weight matrix calculating

The gray evaluation weight of the e-th advocates in $A_{i m}$ proposals by all the experts denoted as $y_{i m}^{e}$, $y_{i j e}=\frac{x_{i j k}}{x_{i j}}$.Consider that there are 4 gray evaluation classes, the gray evaluation weight vector of different gray evaluation classes by $A_{i m}$ donated as $y_{i j}=\left(y_{i j 1}, y_{i j 2}, y_{i j 3}, y_{i j 4}\right)$.At this point that we can get the gray evaluation weight matrix for each evaluation gray class $Z_{j}$ by the respective indicator $A_{i m}$ from $A_{i}$ : 


$$
Y_{i}=\left\{\begin{array}{c}
y_{i 1} \\
y_{i 2} \\
\vdots \\
y_{i m}
\end{array}\right\}=\left\{\begin{array}{cccc}
y_{i 11} & y_{i 12} & y_{i 13} & y_{i 14} \\
y_{i 21} & y_{i 22} & y_{i 23} & y_{i 24} \\
\vdots & \vdots & \vdots & \vdots \\
y_{i j 1} & y_{i j 2} & y_{i j 3} & y_{i j 4}
\end{array}\right\}
$$

IV)Make comprehensive evaluation on $A$ and $A_{4}$

Make comprehensive evaluation on $A_{i}$, let the evaluation result as $Z_{i}$,so $Z_{i}=A_{i} \bullet Y_{i}=\left(z_{i 1}, z_{i 2}, z_{i 3}, z_{i 4}\right)$,The gray evaluation weight of the e-th advocates in $A_{i}$ proposals by evaluator denoted as $Z_{i e}$.

Gray evaluation weight matrix $\mathrm{S}$ is available on $A_{i}$ :

$$
S=\left\{\begin{array}{c}
Z_{1} \\
Z_{2} \\
\vdots \\
Z_{i}
\end{array}\right\}=\left\{\begin{array}{cccc}
Z_{11} & Z_{12} & Z_{13} & Z_{14} \\
Z_{21} & Z_{22} & Z_{23} & Z_{24} \\
\vdots & \vdots & \vdots & \vdots \\
Z_{i 1} & Z_{i 2} & Z_{i 3} & Z_{i 4}
\end{array}\right\}
$$

Make comprehensive evaluation on $\mathrm{A}$, the evaluation result as follows:

$$
S=B \bullet Z=\left(b_{1}, b_{2}, \cdots, b_{i}\right) \bullet\left\{\begin{array}{cccc}
z_{11} & z_{12} & z_{13} & z_{14} \\
Z_{21} & z_{22} & z_{23} & Z_{24} \\
\vdots & \vdots & \vdots & \vdots \\
Z_{i 1} & z_{i 2} & z_{i 3} & Z_{i 4}
\end{array}\right\}=\left(s_{1}, s_{2}, s_{3}, s_{4}\right)
$$

$V)$ Calculate the value of comprehensive evaluation

Assignment each evaluation gray degree grade is based on the "gray level",then we can get the vector of Each evaluation gray class level value $C=(4,3,2,1)$. Comprehensive evaluation value is calculated as follows: $W=S \bullet C^{T}$, where $C^{T}$ means the transpose of each evaluation gray class rank value vector. Obtained the value of $W$ so we can evaluate the pros and cons of internal control by control the levels described above.

\section{CASE ANALYSIS}

The government of City S proposed a low-cost housing project. In order to measure the risk of the project financing, gray evaluation model is set up to evaluate the low-rent housing project financing risks. In order to assess the risks, university professors, government officials and engineering experts who participated in the construction of low-rent housing investment research were invited to made up a judge group to scoring the rates of risk indicators in risk subsets of low-cost financing housing based on their wealthy experience.

The weight of first grade assessment indicator $A_{i}$ and $A_{i m}$ are evaluated by method AHP,get the results as follows: $B=(0.3,0.2,0.2,0.2,0.1)$ is the weight vector of level indicators $A_{i}(\mathrm{i}=1,2,3,4,5)$
The secondary indicators corresponding to the weight vector can be learned respectively through the calculation :

$$
\begin{array}{ll}
B_{1}=(0.4,0.2,0.1,0.2,0.1) & B_{2}=(0.4,0.3,0.3) \\
B_{3}=(0.3,0.3,0.4) & B_{4}=(0.2,0.4,0.4) \\
B_{5}=(0.6,0.4) &
\end{array}
$$

\begin{tabular}{|c|c|c|c|c|c|c|c|c|}
\hline $\begin{array}{c}\text { Index } \\
\text { Number } \\
\mathrm{s}\end{array}$ & 1 & 2 & 3 & 4 & 5 & 6 & 7 & 8 \\
\hline \multirow{5}{*}{$\begin{array}{l}\text { Expert } \\
\text { scoring }\end{array}$} & 2.5 & 3 & 2.5 & 4 & 2.5 & 3 & 3 & 2.5 \\
\hline & 3 & 3 & 2.5 & 3.5 & 4 & 4 & 4 & 3 \\
\hline & 2.5 & 2.5 & 3 & 3 & 4 & 3 & 3.5 & 3 \\
\hline & 4 & 3 & 2.5 & 4 & 3 & 3 & 2.5 & 3 \\
\hline & 3 & 2.5 & 3 & 3 & 3 & 2.5 & 4 & 3 \\
\hline $\begin{array}{c}\text { Index } \\
\text { Number } \\
s\end{array}$ & 9 & 10 & 11 & 12 & 13 & 14 & 15 & 16 \\
\hline \multirow{5}{*}{$\begin{array}{l}\text { Expert } \\
\text { scoring }\end{array}$} & 3 & 3.5 & 3.5 & 3 & 2.5 & 3 & 3.5 & 3.5 \\
\hline & 2.5 & 3 & 2.5 & 3 & 3 & 3.5 & 3 & 3 \\
\hline & 3 & 3 & 3 & 3 & 3 & 2.5 & 3 & 3 \\
\hline & 3 & 3 & 4 & 3 & 3 & 2.5 & 3 & 3 \\
\hline & 3 & 2.5 & 3 & 3 & 3.5 & 3 & 3 & 3 \\
\hline
\end{tabular}

\section{A.The establishment of the evaluation matrix}

Senior experts were invited to evaluate the project risk, the evaluation matrix made up by specific scoring criteria are as the following table:

\section{B. Determine the evaluation gray degree}

The gray type evaluation is divided into four standards and set the serial number represent the "poor", "medium", "good", "excellent" level. Detail relation of whitening weight and gray degree in evaluation was introduced before.

\section{C.Calculating the gray evaluation coefficient}

$x_{11}^{e}$ represents the $e$-th evaluation coefficient in secondary index $A_{11}$ as follows:

$$
\begin{aligned}
& e=1, x_{11}^{1}=f_{1}\left(d_{111}\right)+f_{1}\left(d_{112}\right)+f_{1}\left(d_{113}\right)+f_{1}\left(d_{114}\right)+f_{1}\left(d_{115}\right)=3.75 \\
& x_{11}=x_{11}^{1}+x_{11}^{2}+x_{11}^{3}+x_{11}^{4}=11.583 \\
& x_{11} \text { :The total number of gray degree evaluation }
\end{aligned}
$$

\section{Weight vector and weight matrix}

The gray evaluation weight of the e-th advocates in $A_{11}$ by experts denoted as $y_{11}^{e}$ :

$$
e=1, \quad y_{111}=\frac{x_{111}}{x_{11}}=0.354
$$

calculated by the same method.
$, \mathrm{y}_{112}, \mathrm{y}_{113}, \mathrm{y}_{114}$ can be 
So $y_{11}=(0.354,0.410,0.236,0)$ is the evaluation weight vector corresponding to evaluation price $A_{11}$.

$y_{12}, \cdots y_{15}, y_{21}, y_{22}, \cdots y_{52}$ can be calculated by the same method and then primary index weight matrix $Y_{i}$ that corresponding to all the secondary indexes can be calculated as follows:

$Y_{1}=\left(\begin{array}{llll}0.354 & 0.410 & 0.236 & 0 \\ 0.313 & 0.418 & 0.269 & 0 \\ 0.303 & 0.292 & 0.405 & 0 \\ 0.447 & 0.426 & 0.127 & 0 \\ 0.411 & 0.415 & 0.174 & 0\end{array}\right) \cdots Y_{5}=\left(\begin{array}{llll}0.375 & 0.438 & 0.187 & 0 \\ 0.361 & 0.436 & 0.203 & 0\end{array}\right)$

Making an comprehensive evaluation to primary index weight matrix $A_{1}$ and the result is $Z_{1}=B_{1} \bullet Y_{1}=(0.365,0.404,0.231,0)$

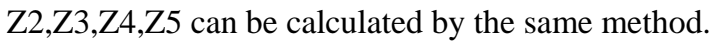

Then the total gray evaluation weight matrix in project risk is $Z=\left[\begin{array}{llll}0.365 & 0.404 & 0.231 & 0 \\ 0.365 & 0.424 & 0.211 & 0 \\ 0.353 & 0.431 & 0.216 & 0 \\ 0.350 & 0.413 & 0.237 & 0 \\ 0.369 & 0.437 & 0.194 & 0\end{array}\right]$ $\mathrm{S}=\mathrm{B} \bullet \mathrm{Z}=(0.354,0.420,0.226,0)$

\section{E. Calculate the value of comprehensive evaluation}

Assignment each evaluation gray class grade based on the "gray level" as $\mathrm{C}=(4,3,2,1)$. Then the value of comprehensive evaluation can be calculated as: $W=S \bullet C^{T}=3.128$

\section{F. Conclusion analysis}

These calculations indicate that the score of low-rent housing PPP project financing risk is 3.128 while 3 is good according to the scoring criteria which suggesting that this project financing risk in good condition and this project is feasible, governments and investors could participate in the construction of this project. However there is still room for improvement, the government should take appropriate measures to control and prevent the risk of low-rent housing project and the share of credit risk weights most according to the index weights. So government should particularly concern about the credit risk, and reasonable policy should be implemented accordingly, so that the impact of the credit risk can be reduced. Government should ensure that the profits returns to investors to make more social capital into the construction of low-rent housing projects and to ensure the smooth implementation of low-cost housing project.

\section{V.CONCLUSION}

The construction of low-rent housing is a welfare undertakings as well as an effective way to solve the housing difficulties of low-income families. The most important issues in the construction of low-rent housing is funds bottlenecks and PPP financing is an effective solution for low-rent housing projects. However, there has been a lot of risk factors inevitably when using PPP financing means. The gray evaluation method is used in this paper to analysis the size of the risk and distinguish whether the project is feasible. This method also provides a theoretical basis for effective decision making by the Government as well as provide new ideas to protect the sustainability for the development of low-cost housing. For the Sustainable development of low-rent housing, the government should also broaden the financing channels, pay attention to learn from foreign experience, improve housing security laws and regulations, and clear the responsibilities and obligations of the government and developers in the process of moving. The limitations of this paper are there is a great initiative of the expert's scoring because the experience of experts is not quite the same and personal feelings are usually putting into the scoring.Further research should be focused on exchanges with more experts and scholars to actively looking for subjective and objective methods and deeper discussion should be taken on the two fronts.

\section{REFERENCES}

[1] Wang Ying.The problems and countermeasures of China's low-rent housing construction under the new situation [J]. Charming China, 2010(04): 31-32

[2] Liu Yachen,Jin Ying.The countermeasures and suggestions of vigorously promoting the housing security work in Liaoning Province [J]. Liaoning Economic,2011(12):32-35.

[3] Wang Qiankun,Wang Shuqiang. PPP mode in the low-rent housing project [J]. Construction Economic,2007 (10) 27-30.

[4] Qiu Yuanhua.The management methods of modern project risk [M].Bei Jing: Science Press.2003 .7-10.

[5] Ding Wenjie.The risk allocation strategy of PPP project about the low-rent housing [J]. Technology Market Economy,2007(4):17-19

[6] Wang Kaifeng,Zhang Xiedong.The evaluation system of production safety based on AHP's construction enterprise [J]. Technology of Wuhan University,2009 (1) :169-171.

[7] Deng Xiaopeng,Yuan Jingfeng,Li Qiming. The value stream analysis of PPP project about indemnificatory housing [J]. Construction Economic,2012,(12):35-39.

[8] $\mathrm{Hu}$ Shenghuang.The multi-level gray evaluation method of Subjective indicators evaluation $[\mathrm{J}]$. Theory and Practice of Systems Engineering,1996,22(1) : 36-41.

[9] Deng Julong. Grey System Theory[M].Wu Han:Huazhong University of Science and Technology Press.1990;3-6. 